\title{
Influence of temperature and concentration on biosynthesis and characterization of zinc oxide nanoparticles using cherry extract
}

\author{
Faezeh Malek Mohammadi ${ }^{1}$ Nahid Ghasemi ${ }^{1}$
}

Received: 8 January 2018 / Accepted: 2 March 2018 / Published online: 19 March 2018

(c) The Author(s) 2018

\begin{abstract}
Due to distinguishing characteristics of nanoparticles (NPs) in terms of size, shape, chemical composition, transmittal and different applications, nanotechnology is considered as an interesting domain of research. Application of metallic NPs is important because of the diminution of dimensions and thus the unique thermal, optical and electronic properties. This research attempts to explore the synthesis of zinc oxide NPs. Zinc oxide NPs have been synthesized using cherry extract under different $\mathrm{pH}$, temperature and concentration and then optimum conditions for the synthesis of them were determined. For further investigations, UV-Vis spectroscopy, scanning electron microscopy (SEM), X-ray diffraction (XRD) and Fourier infrared transformation spectroscopy (FTIR) were used. The solution containing zinc oxide NPs showed a major absorbance of $378 \mathrm{~nm}$ which confirmed the synthesis of zinc oxide NPs, and spherical morphology of NPs was observed in SEM images. Zinc oxide NP sizes were 6.5 and $20.18 \mathrm{~nm}$ which are obtained by UV-Vis spectra and XRD spectrum, respectively. Also, based on the FTIR spectra of the extract obtained before and after the synthesis, the existence of the reducing agents in herbal extract was confirmed. According to this study, the biological synthesis of NPs using plant extracts can be considered as a cost-effective and efficient method of biological synthesis of NPs and it could be an appropriate replacement to typical chemical methods for the synthesis of NPs.
\end{abstract}

Keywords Biosynthesis $\cdot$ Zinc oxide nanoparticles $\cdot$ Cherry extract

\section{Introduction}

Throughout the history of humanity, since the time of Greek, scientists believed that the material can be divided into small pieces so far as the smallest part could not become smaller, and the foundation of the material is based on these particles. Perhaps the Greek philosopher, Democritus, was the father of nanotechnology, since about $400 \mathrm{BC}$. He was the first person which used the term of "atom" to describe the particles that makes matter, which in Greek means indivisible. The starting point and primary development of nanotechnology are not exactly clear. Maybe it can be said that the first nanotechnologists were medieval glaziers. At that time, church glasses were made using gold nanometric particles and very

Nahid Ghasemi

n-ghasemi@iau-arak.ac.ir; anahid3@gmail.com

Faezeh Malek Mohammadi

malek.mohammadi93@gmail.com

1 Department of Chemistry, Arak Branch, Islamic Azad University, Arak, Iran beautiful colored glasses were obtained. The color of these glasses is based on this fact that nanoscale materials do not have the same properties as micro-sized materials [1].

Nanoparticles are the most common elements in nanoscience and nanotechnology, and their interesting properties have led to numerous applications in chemical, medical, pharmaceutical, electronic, and agricultural industries. According to the chemical composition, these particles are divided into metal, ceramic, polymer, and semiconductor. Chemical preparation and solid-state processes, such as grinding and steam condensation, are the usual methods for nanoparticles production, but these methods are not affordable [2]. Nanotechnology has significant advances in nanomaterial production and the use of new methods and materials. By the development of new methods and materials, concern about environmental pollution with nanoparticles produced by chemical methods and the production of harmful sideeffects has been doubled. Safe biological methods can be considered as a substitute for conventional chemical methods for nanoparticles preparation [3]. In recent years, scientific advances in nanotechnology and the use of nanoparticles 
have expanded dramatically, and among nanoparticles, zinc oxide is most likely to be of interest for researchers. Zinc oxide with a broadband gap of (3.3-ev) is a semiconductor, with special usages compared to the micron-sized particles. It is used in various industries such as burning ointments, antibacterial treatments and sunscreen, as strong absorbent UV rays, transistors manufacturing, diodes, props, atomic force microscopes, and display screens. It is used as catalyst [4], photocatalyst [5], absorbent, dental cement manufacturing, solar cell electrodes [6] and gas sensors [7, 8]. They are also used in rubber manufacturing, in the varistors and fire extinguishers, as pigments for dyeing, anti-corrosion coatings, in the glass, ceramic and glaze industry because it can reduce the thermal expansion coefficient and melting point and increase chemical resistance [9]. There are various physical-chemical methods for zinc oxide nanoparticles production [10]; for example, synthesized zinc oxide nanoparticles by ionic liquids, hydro-thermal, direct precipitation, and microwave-assisted methods, respectively [11-14].

It should be noted that synthesized nanoparticles using physical and chemical methods have some limitations, including use of toxic solvents and hazardous chemicals, which is non-eco-friendly [15].

In recent years, green synthesis of nanoparticle has become an interesting topic in nanoscience for researcher. The main goals of green synthesis are (a) producing nanoparticles that are not harmful to environment or human health and (b) producing eco-friendly nanoparticles that can solve environmental problems. Synthesized metallic nanoparticles using plant extracts have attracted great interest with the initiation of green nanotechnology for nanoparticle synthesis,[16]. So there is a great attention to synthesize metal nanoparticles using bio routes $[17,18]$.

During the green synthesis of metal nanoparticles, redox reactions happen in saline solutions, such that the extracts of various organisms include reducing agents that transfer electrons to metal ions and ultimately produce metallic nanoparticles [10, 19, 20].

Biosynthesis of nanoparticles using plants has a priority compared to the chemical and physical methods because of the energy and time costs reduction, and also is an eco-friendly method. There are many reports that plant extracts / different parts of plant have been used for the synthesis of $\mathrm{ZnO}$ NPs, such as Trifolium pratense flower extract [21], Aloe vera leaf extracts [22], Rosa canina fruit extract [23], Physalis alkekengi L. seed extract [24], and Citrus aurantifolia (lemon) peel extract [25], C. aurantifolia [26], dried sap of shoots and roots of Astragalus gummifer [27], Hibiscus rosasinensis [28], leaf extract of Azadirachta indica [29], Leaf extract of Camellia sinensis [30], Zea mays leaf extract [31], aqueous extract of Abutilon indicum [32] and Dittrichia graveolens aqueous extract [33]. The synthesis of ZnO NPs was studied with the leaf extract of Ocimum tenuiflorum and was characterized by scanning electron microscopy (SEM), Fourier infrared transformation spectroscopy (FTIR) and X-ray diffraction (XRD). The SEM image showed hexagonal shape and NP with diameter range of 11-25 $\mathrm{nm}$ [34]. The synthesized $\mathrm{ZnO}$ nanoparticles from leaf extract of Olea Europaea were characterized using by FTIR, UV-Vis, XRD and SEM techniques. The average size of particles was found to be $500 \mathrm{~nm}$ and the thicknesses was about $20 \mathrm{~nm}$ by SEM studies. FT-IR analysis of aqueous Olea Europaea leaf extract showed the presence of surface-active molecules (phytoconstituents) such as aldehydes, amines, phenols, and alcohols that caused zinc oxide nanosheet stabilization [35, 36].

Biosynthesis of $\mathrm{ZnO}$ nanoparticles was widely studied before, but to our best knowledge there are no reports on its biosynthesis using cherry extract. In this study, the biological synthesis of zinc oxide NPs using cherry fruit extract has been investigated. The reason for this choice is that the cherry contains niacin, protein, vitamins $(\mathrm{A}, \mathrm{B}, \mathrm{C})$ and riboflavin as well as mineral salts such as protein, sugar, water, nitrogen, hydrocarbon, fatty substances, arabinose, cellulose, carotene and cyanuric acid [37]; this plant has some bio-molecules that can act as capping and reducing agents which increase the rate of stabilization and reduction of NPs. In this study, the effects of temperature, concentration and $\mathrm{pH}$ were investigated, eventually; synthesized NPs were evaluated by ultraviolet (UV-Vis) spectroscopy, SEM, XRD and FTIR.

\section{Experimental}

\section{Materials and methods}

In this study, cherry fruit was purchased from local suppliers (Arak-Iran).All chemicals were purchased from Merck Co. Doubly distilled water was used in all the experiments.

The powder X-ray diffraction (XRD) analysis was performed by means of a XPERT Pro XRD Machine, manufactured by Panalytical, Netherlands. The morphologies were characterized by a scanning electron microscope model VEGA3-TESCAN manufactured by Elektonen-optik-service Gmbh Germany, and Shin SAENG Furnace Model SEF201 manufactured by Muffle Furnace Korean Company, and 632 Metrohm $_{\mathrm{P}} \mathrm{H}$ meter, Herisau, Switzerland, the Varian Cary-300 spectrophotometer, American Shaker made by IKA, and Perkin Elmer RXI FT-IR spectrometer were used in this study.

\section{The extract preparation}

2.5 kilograms of cherry water were filtered by Whatman filter paper 42 then it was boiled for $15 \mathrm{~min}$, so extract solution was prepared from concentrated solution. 


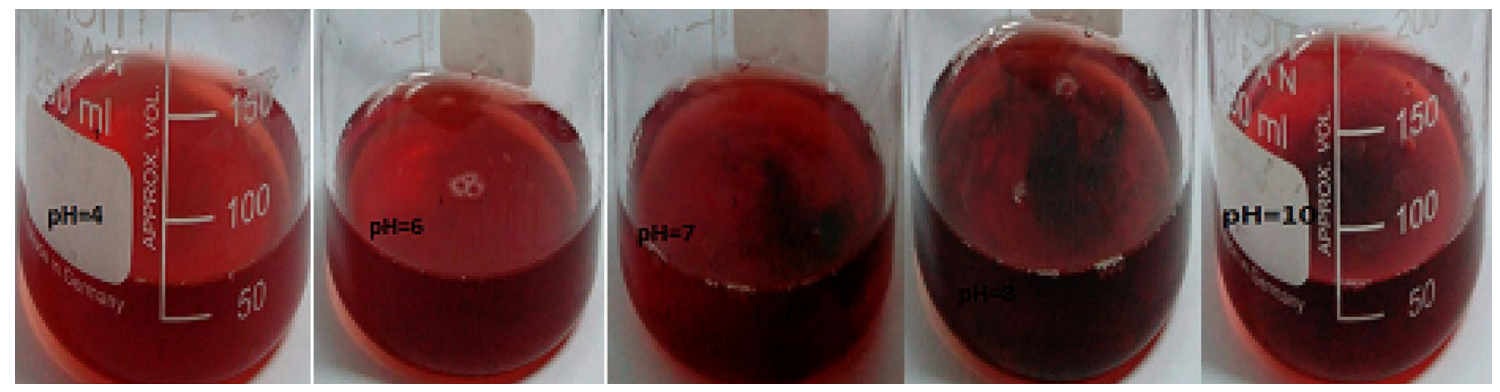

Fig. 1 Influence of $\mathrm{pH}$ on $\mathrm{ZnO}$ nanoparticles synthesis via green route using cherry extract

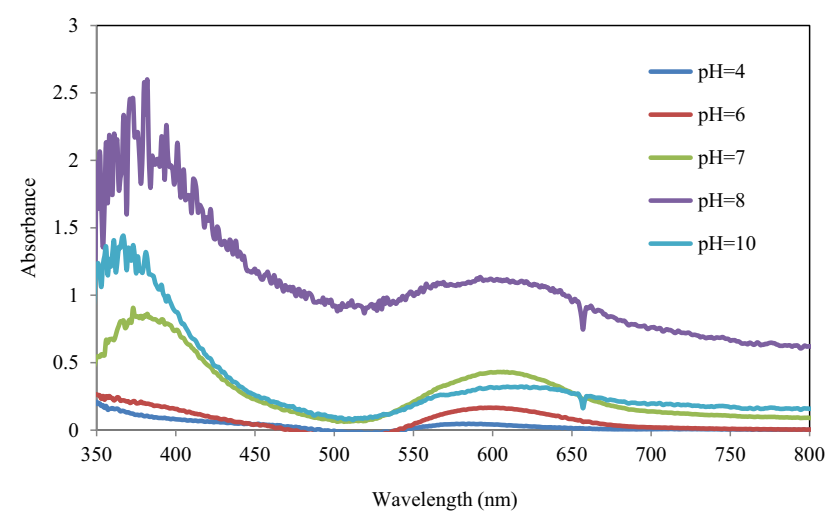

Fig. 2 UV-Vis absorption spectrum of synthesized $\mathrm{ZnO}$ nanoparticles at different $\mathrm{pH}$ using cherry extract

\section{Influence of pH on zinc oxide nanoparticles synthesis by cherry extract}

According to studies by other researchers [38], in low $\mathrm{pH}$ regions, $\mathrm{ZnO}$ is highly soluble while at high $\mathrm{pH}$, partial disaggregation occurred. So we chose the $\mathrm{pH}$ domain ranging between 4 and 10 .

$10 \mathrm{ml}$ of as-prepared extract solution is poured into the 5 beaker and then $30 \mathrm{ml}$ of $0.3 \mathrm{M} \mathrm{Zn}\left(\mathrm{NO}_{3}\right)_{2} \cdot 6 \mathrm{H}_{2} \mathrm{O}$ was added to them and stirred with the stirring rate of $150 \mathrm{rpm}$ for 30 min at $25^{\circ} \mathrm{C}$ with $\mathrm{pH}$ value of (4-6-7-8-10) (Fig. 1), then left them in a dark place for $12 \mathrm{~h}$; after that solutions were centrifuged with stirring rate of $5000 \mathrm{rpm}$ to separate the obtained precipitate. For this purpose UV-Vis spectrophotometry has been used in the range of $350-800 \mathrm{~nm}$ (Fig. 2). Finally, the optimum pH was selected (Fig. 3). To adjust $\mathrm{pH}, 0.1 \mathrm{M}$ Nitric acid and $0.1 \mathrm{M} \mathrm{NaOH}$ were used.

\section{Influence of temperature on zinc oxide nanoparticles synthesis by cherry extract}

$10 \mathrm{ml}$ of as-prepared extract solution is poured into the 3 beaker and then $30 \mathrm{ml}$ of $0.3 \mathrm{M} \mathrm{Zn}\left(\mathrm{NO}_{3}\right)_{2} \cdot 6 \mathrm{H}_{2} \mathrm{O}$ was added to them and stirred with the stirring rate of $150 \mathrm{rpm}$ for

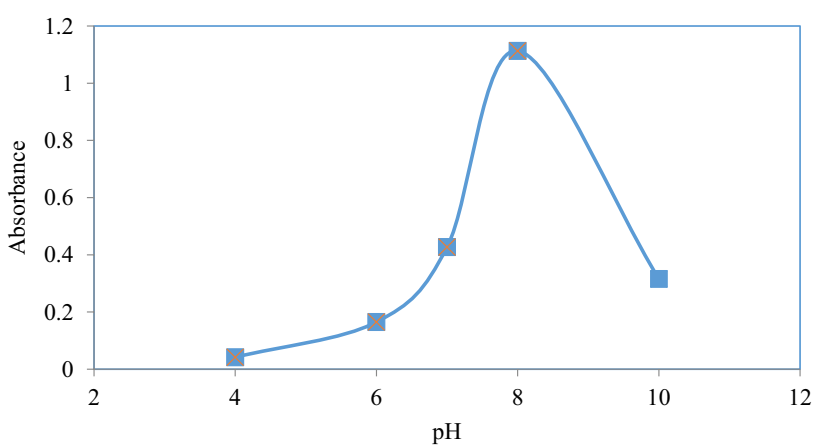

Fig. $3 \mathrm{pH}$ vs adsorption spectrum for $\mathrm{ZnO}$ nanoparticles synthesized using by cherry extract

$30 \mathrm{~min}$ at different temperatures $\left(25,60\right.$ and $\left.90{ }^{\circ} \mathrm{C}\right)$ then left them in a dark place for $12 \mathrm{~h}$; after that solutions were centrifuged with stirring rate of $5000 \mathrm{rpm}$ to separate the obtained precipitate. After drying and calcining, the precipitate was characterized by SEM, according to the results, the optimum temperature was selected for further experiments (Fig. 4a-c).

\section{Influence of metal salt solution concentration on zinc oxide nanoparticles synthesis by cherry extract}

To study the effect of concentration of zinc nitrate solution on biosynthesis of $\mathrm{ZnO}$ nanoparticles, according to previous studies [39], different concentrations were selected. During the synthesis, $10 \mathrm{ml}$ of as-prepared extract solution is poured into the 4 beaker and then $30 \mathrm{ml}$ of $\mathrm{Zn}\left(\mathrm{NO}_{3}\right)_{2} \cdot 6 \mathrm{H}_{2} \mathrm{O}$ with different concentration $(0.005,0.02,0.05$ and $0.3 \mathrm{M})$ was added to them and stirred with the stirring rate of $150 \mathrm{rpm}$ for $30 \mathrm{~min}$ at $25^{\circ} \mathrm{C}$ (Fig. 5) then left them in a dark place for $12 \mathrm{~h}$; after that solutions were centrifuged with stirring rate of $5000 \mathrm{rpm}$ to separate the obtained precipitate. After drying and calcining, the sediment was characterized by SEM (Fig. 6a-d). According to the results, the optimum metal salt solution concentration was selected for further experiments. 

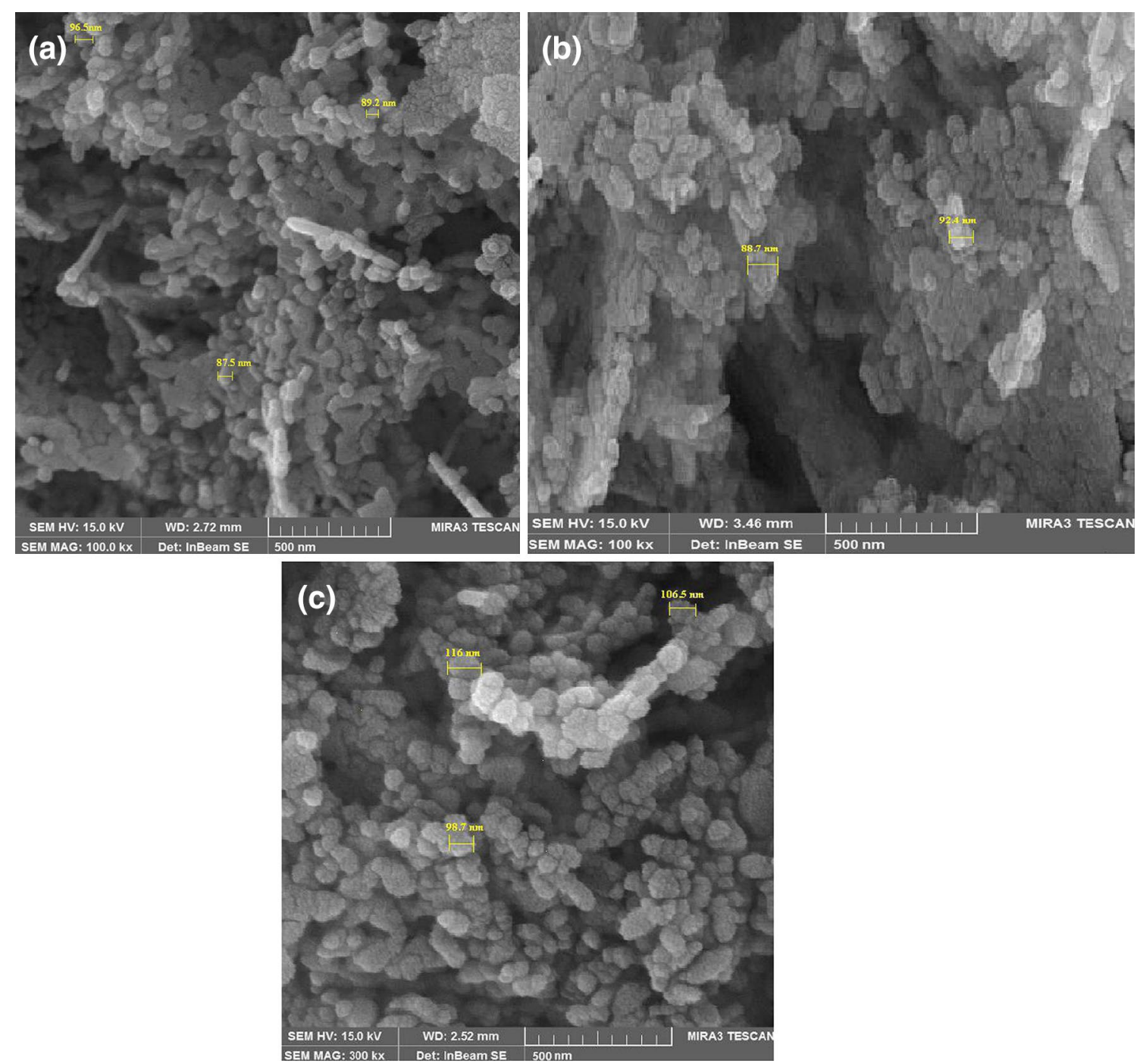

Fig. 4 Scanning electron micrograph (SEM) of synthesized $\mathrm{ZnO}$ nanoparticles using zinc nitrate $(0.3 \mathrm{M})$ with $\mathrm{pH}=8$, a at $25^{\circ} \mathrm{C}$, b $60{ }^{\circ} \mathrm{C}$ and $\mathbf{c}$ $90^{\circ} \mathrm{C}$

\section{Characterization of metal nanoparticle}

After determining the optimum conditions $(\mathrm{pH}=8$, $\left.t=25{ }^{\circ} \mathrm{C}, C=0.005 \mathrm{M}\right), \mathrm{ZnO}$ nanoparticles were again synthesized using cherry extract and evaluated by UV-Vis (between 350 and $500 \mathrm{~nm}$ ), FTIR and XRD techniques.
Fig. 5 Influence of metal salt solution concentration on $\mathrm{ZnO}$ nanoparticles synthesis via green route using cherry extract
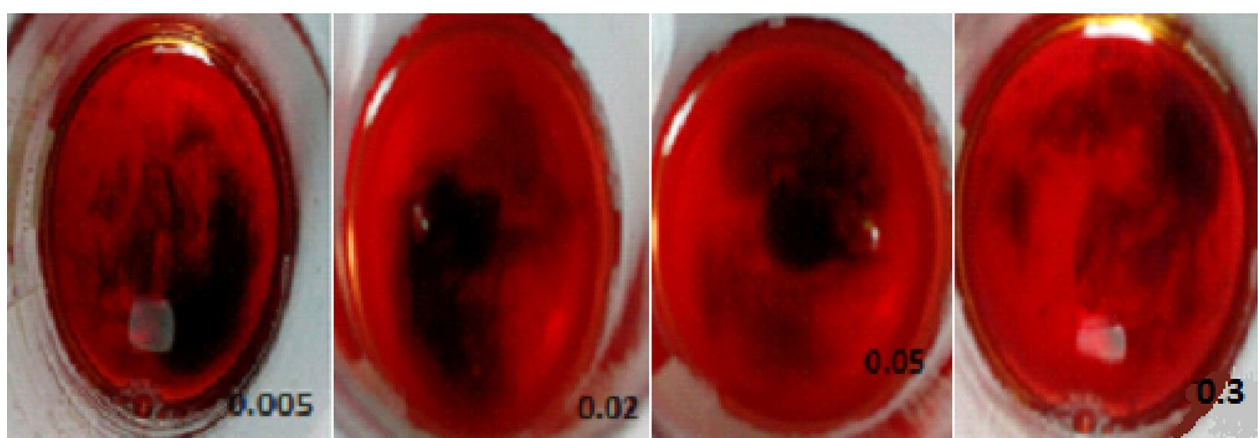

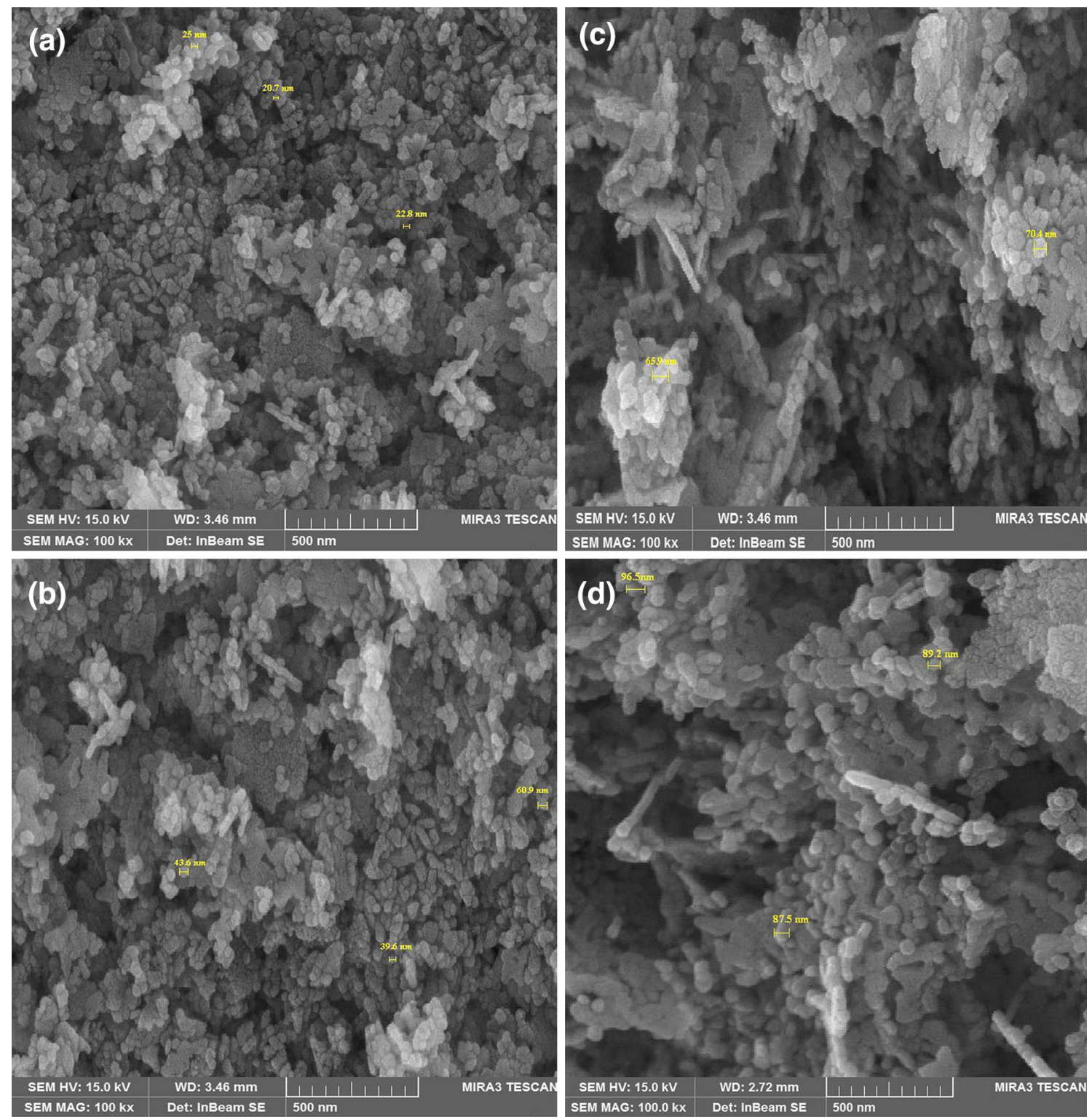

Fig. 6 Scanning electron micrograph of biosynthesized $\mathrm{ZnO}$ nanoparticles at $25{ }^{\circ} \mathrm{C}$ and $\mathrm{pH}=8$ using different concentration of zinc nitrate, a $0.005 \mathrm{M}, \mathbf{b} 0.02 \mathrm{M}, \mathbf{c} 0.05 \mathrm{M}$ and d $0.3 \mathrm{M}$

\section{Results and discussion}

\section{Influence of pH on zinc oxide nanoparticles synthesis by cherry extract}

$\mathrm{pH}$ is another important factor affecting the reduction of metal ions. The major effect of $\mathrm{pH}$ is changing the electrical charges of biomolecules which might change their reducing and capping ability and then the growth of nanoparticles [40]. The effect of $\mathrm{pH}$ on the reduction of metal ions was studied by UV-Vis spectroscopy and is shown in Fig. 2. It is well known that a strong absorption band in the range of $300-550 \mathrm{~nm}$ is due to $\mathrm{ZnO}$ nanoparticles [41]. At $\mathrm{pH}=4.0$ in the range of 350-550 $\mathrm{nm}$, no main absorption peak was observed but a main absorption peak appeared about $373 \mathrm{~nm}$ when $\mathrm{pH}$ increased from 4 to 10 indicating the formation of $\mathrm{ZnO}$ nanoparticles. it was observed that higher $\mathrm{pH}(\mathrm{pH} 8)$ enhances the rate of reduction as the colour of the solution turned colloidal brown more quickly compared to a solution of lower $\mathrm{pH}$ (Fig. 1). With increase of $\mathrm{pH}$ from 4 to 8 , surface plasmon resonance (SPR) absorption peak shifted to larger wavelength indicating the formation of larger size $\mathrm{ZnO}$ nanoparticles and the red shift; however with increase of $\mathrm{pH}$ from 8 to 10, SPR absorption peak shifted to the blue shift that will be due to smaller size of $\mathrm{ZnO}$ nanoparticles [42]. It is found that at the strongly alkaline condition, the 
more abundance $\mathrm{OH}$ ions in the solution, form a complex with $\mathrm{Zn}^{2+}$ cations as the molecules $\mathrm{Zn}[\mathrm{OH}]_{4}^{2-}$ and $\mathrm{Zn}(\mathrm{OH})_{2}$, which could restrain the production of $\mathrm{ZnO}$ nanoparticles $[43,44]$. The area under the SPR-peak in the UV-Vis spectra directly depends on the shape and size of the metal nanoparticles as well as dielectric constant of the metal and the surrounding medium in aqueous suspensions [45] and causes the spectrum to be noisy. The optimum $\mathrm{pH}$ for nanoparticles synthesis depends on the substrate or stabilizing agent which is used in the synthesis. According to the obtained results from UV-Vis spectroscopy and $\mathrm{pH}$-absorption spectrum of synthesized $\mathrm{ZnO}$ nanoparticles (Fig. 2), it was found that the best $\mathrm{pH}$ for synthesis of hexagonal small size nanoparticles via green route using cherry extract as a reducing and stabilizing agent is $\mathrm{pH}=8$ (Fig. 3).

\section{Influence of temperature on zinc oxide nanoparticles synthesis by cherry extract}

It has been demonstrated that biosynthesized nanoparticles size can be controlled by changing the solution temperature [42, 46, 47]. Figure 4 shows SEM images of $\mathrm{ZnO}$ nanoparticles at different temperatures $\left(25,60\right.$, and $\left.90^{\circ} \mathrm{C}\right)$. It can be observed that the increase in temperature caused the increase in the size of ZnO NPs $(87.5-116 \mathrm{~nm})$ which indicate the reduction rate of metal ions increased by temperature; because high temperature will lead to too high reaction kinetics. It is impossible to control the growth step of the crystallization process in reactions with fast kinetics; on the other hand, an explanation for this is that cherry extract is a reducing agent which is rich in ascorbic acid [48] and this acid becomes slightly unstable at higher temperatures [49] and leads to a poor reduction process, uncontrolled and fast aggregation.

SEM images of nanoparticles (Fig. 4) in this synthesis show their dimensions and according to SEM images, the morphological surface of $\mathrm{ZnO}$ nanoparticles was optimized at $25{ }^{\circ} \mathrm{C}$.

\section{Influence of metal salt solution concentration on zinc oxide nanoparticles synthesis by cherry extract}

Figure 5 shows effect of zinc nitrate concentration in the $\mathrm{ZnO}$ NPs biosynthesis using extract of cherry at different concentration $(0.005,0.02,0.05$ and $0.3 \mathrm{M})$. When zinc ions concentration was increased from 0.005 to $0.3 \mathrm{M}$, biochemical reduction starts immediately, and the lower quantities of hexagonal structural nanoparticles formed with an average size of 20.7-96.5 nm (Fig. 5a-d) that this is mainly due to the formation of large anisotropic particles. This perhaps may occur because by fixing the quantity of cherry extract, the concentration of groups/bio-molecules such as protein, vitamins (A, B, C) and sugars which capped and stabilize the nanoparticle. Also, these SEM images show that the concentration of biosynthesis $\mathrm{ZnO}$ nanoparticles occurred quickly and the larger size of them formed that due to the occurrence of competition between zinc ions and functional groups of cherry extract and rate of reduction also increased [50,51]. Thus, the optimum concentration of zinc nitrate for $\mathrm{ZnO}$ biosynthesized nanoparticle via green route using cherry extract was found to be $0.005 \mathrm{M}$.

\section{UV-Vis analysis}

The UV-Vis spectra of $\mathrm{ZnO}$ nanoparticles biosynthesized using cherry extract is shown in Fig. 7. The metal nanoparticles have a SPR broad absorption in the UV-Visible region $[52,53]$. From this UV spectra, SPR peak for $\mathrm{ZnO}$ nanoparticles is obtained at $378 \mathrm{~nm}$ indicating combined vibration of electron of nanoparticle with the light wave [54]. Similar results were reported by Ghorbani et al. [41]. The following equation (Eq. 1) is used to find the size of the nanoparticle from the absorbance spectra (Fig. 7) [55, 56].

$r(\mathrm{~nm})=\frac{-0.3049+\sqrt{-26.23012+10,240.72 / \lambda_{\mathrm{p}}(\mathrm{nm})}}{-6.3829+2483.2 / \lambda_{\mathrm{p}}(\mathrm{nm})}$

where $r$ and $\lambda_{\mathrm{p}}$ are the particle radius and the peak absorbance wavelength $(\mathrm{nm})$, respectively. The absorbance peak at $378 \mathrm{~nm}$ is related to the particle size of $6.5 \mathrm{~nm}$.

\section{X-ray diffraction analysis}

According to the XRD analysis and the obtained results pattern, the sharp and high peak indicates the crystallinity of the prepared nanoparticle (Fig. 8).

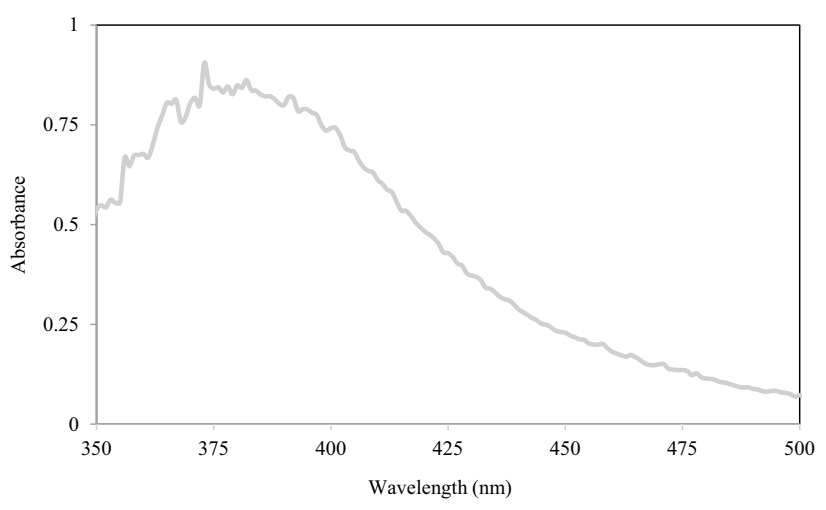

Fig. $7 \mathrm{UV}-\mathrm{Vis}$ spectra of $\mathrm{ZnO}$ nanoparticles synthesized by cherry extract at optimal condition, $(10 \mathrm{ml}$ of cherry extract, $30 \mathrm{ml}$ of $0.005 \mathrm{M}$ Zinc nitrate solution, $\mathrm{pH}=8$, temperature $25^{\circ} \mathrm{C}$, time $=12 \mathrm{~h}$ ) 
The diffraction peaks at $2 \theta$ values of $32.04,34.675$, 36.502, 47.773, 56.799, 63.100, 68.204, 69.394, 72.764, 77.147 correspond to (100), (002), (101), (102), (110), (103), (112), (201), (004) and (202), respectively, which are characteristic of the hexagonal structure of $\mathrm{ZnO}$ nanoparticles. All peaks were well matched with JCPDS card No. 80-0075.

Also, according to the Scherer-Debye equation (Eq. 2):

$D=\frac{K \times \lambda}{\beta \times \cos \theta}$

in which the parameters are as follows, respectively: $D$ is the size of the crystal, its unit is equal to $\lambda$ unit and is usually angstrom or $\mathrm{nm} ; \lambda$ is the $\mathrm{X}$-ray wavelength; $K$ is a dimensionless shape factor, with a value close to unity; $\beta$ is the full width at half maximum (FWHM); $\theta$ is the peak position on the horizontal axis of diffraction pattern, which, if the horizontal axis is $2 \theta$. It should be divided into two to get $\theta$. With the necessary calculations, the zinc oxide nanoparticle average size is $20.18 \mathrm{~nm}$. Similar results of Nyctanthes arbor-tristis flower extract [57] and Corymbia citriodora leaf extract [58] have been reported for synthesizing zinc oxide nanoparticles.

\section{Fourier transform infrared spectroscopy analysis}

The FT-IR spectrum of the extract sample before and after the synthesis of metal nanoparticles is shown in Figs. 9 and 10. A broad peak within the wavenumbers ranging from
3650 to $3200 \mathrm{~cm}^{-1}$ attributed to the $\mathrm{O}-\mathrm{H}$ functional group, peak in the range of $2850-3000 \mathrm{~cm}^{-1}$ can be assigned to the $\mathrm{C}-\mathrm{H}$ alkane functional group. Six peaks within the wavenumbers ranging from 3500 to 3300,1630 to 1850,1680 to 1600,1450 to 1340,1350 to 1000 and 800 to $600 \mathrm{~cm}^{-1}$ can be assigned to the $\mathrm{N}-\mathrm{H}, \mathrm{C}=\mathrm{O}$ (The carbonyl stretch of a carboxylic acid), $\mathrm{C}=\mathrm{C}, \mathrm{CH}_{3}, \mathrm{C}-\mathrm{N}$ and $\mathrm{Cl}$ respectively. The band at $825 \mathrm{~cm}^{-1}$ is due to asymmetrical and symmetrical stretching of zinc carboxylates resulting in the involvement of carboxylic groups in protein of cherry leaf extract. The peak which is observed from 400 to $500 \mathrm{~cm}^{-1}$ is due to $\mathrm{Zn}-\mathrm{O}$ vibrations of $\mathrm{ZnO}$ nanoparticles, as observed earlier [31, 59-61]. Peak at $1627.24,3416.92 \mathrm{~cm}^{-1}$ corresponds to $\mathrm{C}=\mathrm{O}$ stretching and $\mathrm{O}-\mathrm{H}$ stretching of organic compound. FTIR analysis of zinc nanoparticles indicated that they might be surrounded by these organic molecules [62].

According to the comparison of two spectra, the absence of some peaks or the presence of some new peaks in the spectrum of the extract after nanoparticle synthesis is an evidence for the performance of the reducing agents and nanoparticles formation.

\section{Conclusion}

Green nanotechnology means "the development of clean technologies" for reducing human and environmental health threats associated with the fabrication and use of nanotechnology products, as well as replace existing products with
Fig. 8 X-ray diffraction pattern of zinc oxide nanoparticles synthesized by green route using cherry extract at optimal condition, $(10 \mathrm{ml}$ of cherry extract, $30 \mathrm{ml}$ of $0.005 \mathrm{M}$ Zinc nitrate solution, $\mathrm{pH}=8$, temperature $25^{\circ} \mathrm{C}$, time $=12 \mathrm{~h}$ )

Fig. 9 FT-IR spectra of $\mathrm{ZnO}$ nanoparticles synthesized by cherry extract at optimal condition, (10 $\mathrm{ml}$ of cherry extract, $30 \mathrm{ml}$ of $0.005 \mathrm{M}$ zinc nitrate solution, $\mathrm{pH}=8$, temperature $25^{\circ} \mathrm{C}$, time $=12 \mathrm{~h}$ )
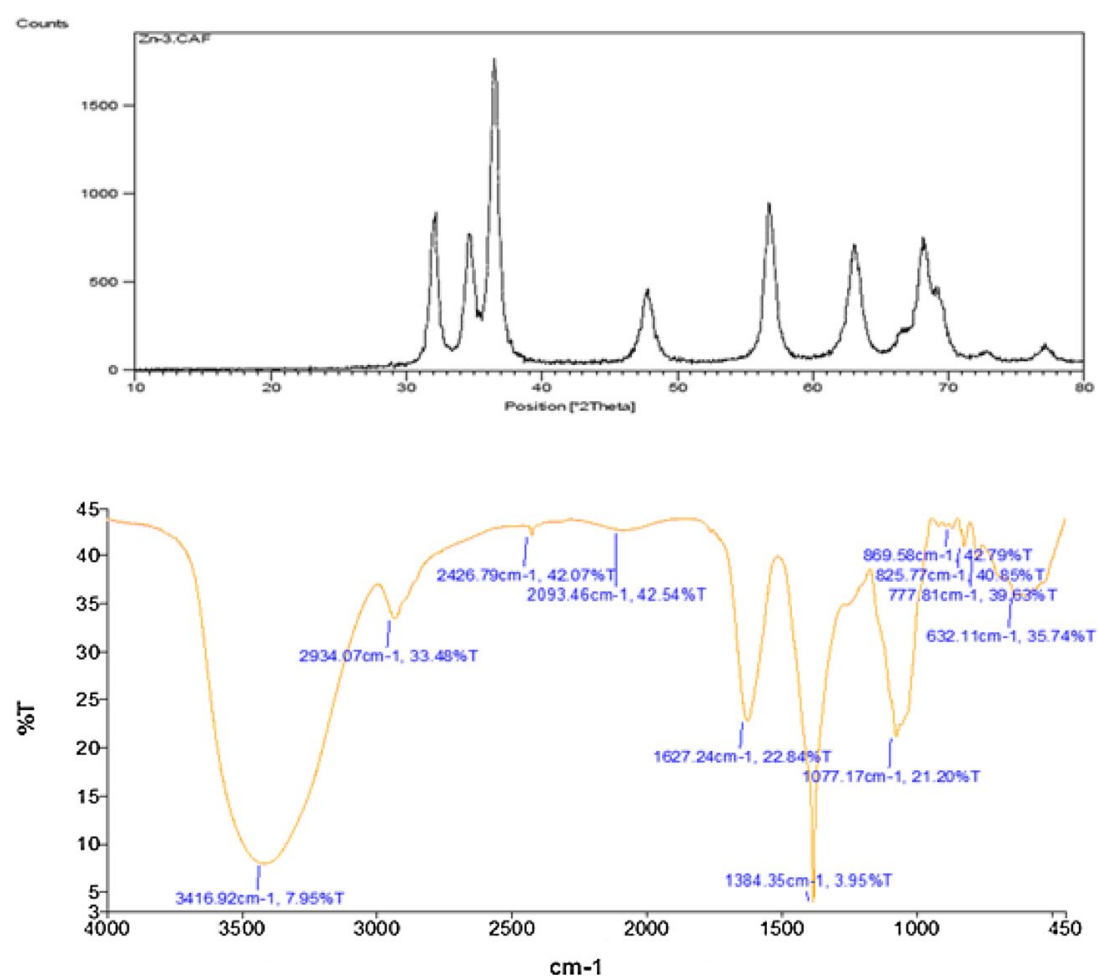
Fig. 10 FT-IR spectra of pure cherry extract

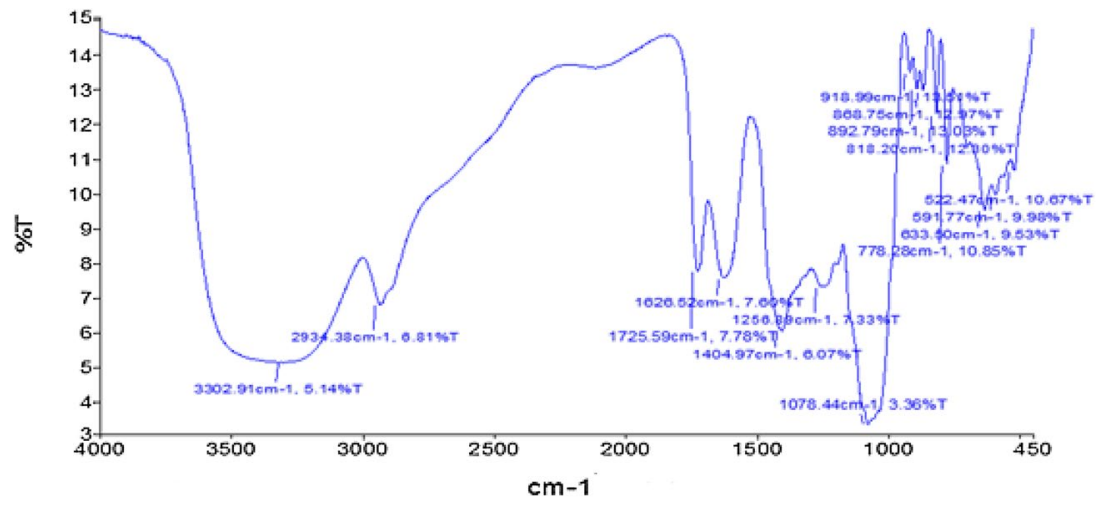

new nano-products that are eco-friendly. Main goals of green nanotechnology are: (a) production of nano-materials and products which are not harmful to environment or human health, (b) production of nano products that provide solutions for environmental problems.

In this work, using UV-Vis spectrophotometry in the range of 350-800 nm, biosynthesis of zinc oxide nanoparticles by cherry extract was studied. To achieve optimal synthesis conditions, effective parameters such as $\mathrm{pH}$, temperature and concentration of zinc nitrate were investigated. In optimum conditions, hexagonal zinc oxide nanoparticles with an average size of $20.18 \mathrm{~nm}$, using $10 \mathrm{ml}$ of cherry extract and $30 \mathrm{ml}$ of $0.005 \mathrm{M}$ zinc nitrate at $\mathrm{pH}=8$, temperature $=25^{\circ} \mathrm{C}$ and time $=12 \mathrm{~h}$ were synthesized. The obtained results from UV-Vis spectrophotometry, SEM, XRD and FTIR analysis confirmed the efficiency of cherry extract in the synthesis of high purity, crystalline zinc oxide nanoparticles. Also, in the FTIR spectrum of the extract, reducing functional groups for zinc ions reduction was observed. According to the results, this fruit is capable of synthesizing nanoparticles, and since there are no reports about this plant, the results clearly show the good functioning of this plant. Therefore, it can be concluded that synthesis of nanoparticles using herbal extracts instead of chemical and physical methods for preparation of these nanoparticles is an appropriate alternative. Finally, in this study, it was found that zinc oxide nanoparticle can be synthesized by green chemistry route without any harmful chemicals.

Open Access This article is distributed under the terms of the Creative Commons Attribution 4.0 International License (http://creativeco mmons.org/licenses/by/4.0/), which permits unrestricted use, distribution, and reproduction in any medium, provided you give appropriate credit to the original author(s) and the source, provide a link to the Creative Commons license, and indicate if changes were made.

\section{References}

1. Varadan, V.K., Pillai, A.S., Mukherji, D., Dwivedi, M., Chen, L.: Nanoscience and Nanotechnology in Engineering. World Scientific, Singapore (2010)

2. Shankar, S.S., Rai, A., Ankamwar, B., Singh, A., Ahmad, A., Sastry, M.: Biological synthesis of triangular gold nanoprisms. Nat. Mater. 3, 482-488 (2004)

3. Mukherjee, P., Ahmad, A., Mandal, D., Senapati, S., Sainkar, S.R., Khan, M.I., Parishcha, R., Ajaykumar, P.V., Alam, M., Kumar, R., Sastry, M.: Fungus-mediated synthesis of silver nanoparticles and their immobilization in the mycelial matrix: a novel biological approach to nanoparticle synthesis. Nano Lett. 1, 515-519 (2001)

4. Huang, W.J., Fang, G.C., Wang, C.C.: A nanometer-ZnO catalyst to enhance the ozonation of 2,4,6-trichlorophenol in water. Colloid. Surf. A 260, 45-51 (2005)

5. Annapoorani, R., Dhanjeyan, M.R., Renganathan, R.: An investigation on $\mathrm{ZnO}$ photocatalysed oxidation of uracil. J. Photochem. Photobiol. A 111, 215-221 (1997)

6. Matsubara, K., Fon, P., Iwata, K., Yamada, A., Sakurai, K., Tampo, H., Niki, S.: ZnO transparent conducting films deposited by pulsed laser deposition for solar cell applications. Thin Solid Films 431, 369-372 (2003)

7. Zhang, Q., Xie, C., Zhang, S., Wang, A., Zhu, B., Wang, L., Yang, Z.: Identification and pattern recognition analysis of Chinese liquors by doped nano $\mathrm{ZnO}$ gas sensor array. Sens. Actuators B 110, 370-376 (2005)

8. Lin, H.M., Tzeng, S.J., Hsiau, P.J., Tsia, W.L.: Electrode effects on gas sensing properties of nanocrystalline zinc oxide. Nanostruct. Acta Mater. 10, 465-477 (1998)

9. Sanches, L., Peral, J., Domenech, X.: Degradation of 2,4-dichlorophenoxyacetic acid by in situphotogenerated fenton reagent. Electro. Chem. Acta 41, 1981-1985 (1996)

10. Hosseinkhani, P., Zand, A., Imani, S., Rezayi, M., Rezaei Zarchi, S.: Determining the antibacterial effect of $\mathrm{ZnO}$ nanoparticle against the pathogenic bacterium, Shigella dysenteriae (type 1). Int. J. Nano Dimens. 1, 279-285 (2011)

11. Sabbaghan, M., Shahvelayati, A., Banihashem, S.: Green synthesis of symmetrical imidazolium based ionic liquids and their application in the preparation of $\mathrm{ZnO}$ nanostructures. Ceram. Int. 42, 3820-3825 (2016)

12. Tam, K.H., Djurisic, A.B., Chan, C.M.N., Xi, Y.Y., Tse, C.W., Leung, Y.H., et al.: Antibacterial activity of $\mathrm{ZnO}$ nanorods prepared by a hydrothermal method. Thin Solid Films 516(18), 6167-6174 (2008)

13. Malakootian, M., Tolabi, A.: Determining and comparing the effect of nanoparticle Cuo, $\mathrm{TiO}_{2}$ And $\mathrm{ZnO}$ in removing gram 
positive and negative bacteria from wastewater. Tolooe Behdasht 2-3(29), 1-10 (2010)

14. Ma, J., Liu, J., Bao, Y., Zhu, Z., Wang, X., Zhang, J.: Synthesis of large-scale uniform mulberry like $\mathrm{ZnO}$ particles with microwave hydrothermal method and its antibacterial property. Ceram. Int. 39(3), 2803-2810 (2013)

15. Ahmed, S., Annu, K., Chaudhry, S.A., Ikram, S.: A review on biogenic synthesis of $\mathrm{ZnO}$ nanoparticles using plant extracts and microbes: a prospect towards green chemistry. J. Photochem. Photobiol. B 166, 272-284 (2017)

16. Betts, K.: A greener route to gold nanoparticles. Environ. Sci. Technol. 39(5), 104-105 (2005)

17. Korbekandi, H., Iravani, S., Abbasi, S.: Production of nanoparticles using organisms. Crit. Rev. Biotechnol. 29(4), 279-306 (2009)

18. Chandran, S.P., Chaudhary, M., Pasricha, R., Ahmad, A., Sastry, M.: Synthesis of gold nanotriangles and silver nanoparticles using Aloevera plant extract. Biotechnol. Prog. 22, 577-583 (2006)

19. Seven, O., Dindar, B., Aydemir, S., Metin, D., Ozinel, M., Icli, S.: Solar photocatalytic disinfection of a group of bacteria and fungi aqueous suspensions with $\mathrm{TiO}_{2}, \mathrm{ZnO}$ and Sahara desert dust. J. Photochem. Photobiol. A 165, 103-107 (2004)

20. Erb, U., Aust, K., Palumbo, G.: Nanostructured Materials Processing Properties and Potential Applications, vol. 17, no. 2, pp. 179-222. Noyes Publications, New York (2002)

21. Dobrucka, R., Długaszewska, J.: Biosynthesis and antibacterial activity of $\mathrm{ZnO}$ nanoparticles using Trifolium pratense flower extract. Saudi J. Biol. Sci. 23, 517-523 (2016)

22. Ali, K., Dwivedi, S., Azam, A., Saquib, Q., Al-Said, M.S., Alkhedhairy, A.A., et al.: Aloe vera extract functionalized zinc oxide nanoparticles as nanoantibiotics against multidrug resistant clinical bacterial isolates. J. Colloid Interface Sci. 472, 145-156 (2016)

23. Jafarirad, S., Mehrabi, M., Divband, B., Kosari-Nasab, M.: Biofabrication of zinc oxide nanoparticles using fruit extract of Rosa canina and their toxic potential against bacteria. A mechanistic approach. Mater. Sci. Eng. C 59, 296-302 (2016)

24. Qu, J., Yuan, X., Wang, X., Shao, P.: Zinc accumulation and synthesis of $\mathrm{ZnO}$ nanoparticles using Physalis alkekengi L. Environ. Pollut. 159, 1783-1788 (2011)

25. Çolak, H., Karaköse, E.: Green synthesis and characterization of nanostructured $\mathrm{ZnO}$ thin films using Citrus aurantifolia (lemon) peel extract by spin-coating method. J. Alloys Compd. 690, 658$662(2017)$

26. Vidya, C., Hiremath, S., Chandraprabha, M.N., Venugopal, I., Jain, A., Bansal, K.: Green synthesis of $\mathrm{ZnO}$ nanoparticle by Calotropis gigantea. Int. J. Curr. Eng. Technol. 4, 118-120 (2013)

27. Darrudi, M., Oskuee, R.K., Kargar, H.: Sol-gel synthesis, characterization and neurotoxicity effect of zinc oxide nanoparticles using gum tragacanth. Ceram. Int. 40, 4827-4831 (2013)

28. Devi, R.S., Gayathri, R.: Green synthesis of zinc oxide nanoparticles by using Hibiscus rosa-sinensis. Int. J. Curr. Eng. Technol. 4, 2444-2446 (2014)

29. Oudhia, A., Kulkarni, P., Sharma, S.: Green synthesis of $\mathrm{ZnO}$ nanotubes for bioapplications. Int. J. Curr. Eng. Technol. 1, 280 281 (2015)

30. Senthilkumar, S.R., Sivakumar, T.: Green tea Camellia sinensis mediated synthesis of zinc oxide nanoparticles and studies on their antimicrobial activities. Int. J. Pharm. Pharm. Sci. 6, 461-465 (2014)

31. Saranya, S., Eswari, A., Gayathri, E., Eswari, S., Vijayarani, K.: Green synthesis of metallic nanoparticles using aqueous plant extract and their antibacterial activity. Int. J. Curr. Microbiol. App. Sci. 6(6), 1834-1845 (2017)

32. Ahmad Khan, S., Noreen, F., Kanwal, S., Iqbal, A., Hussain, Gh: Green synthesis of $\mathrm{ZnO}$ and $\mathrm{Cu}$-doped $\mathrm{ZnO}$ nanoparticles from leaf extracts of Abutilon indicum, Clerodendrum infortunatum, Clerodendrum inerme and investigation of their biological and photocatalytic activities. Mater. Sci. Eng. C 82, 46-59 (2018)

33. Hoseinpour, V., Souri, M., Ghaemi, N., Shakeri, A.: Optimization of green synthesis of $\mathrm{ZnO}$ nanoparticles by Dittrichia graveolens (L.) aqueous extract. Health Biotechnol. Biopharma. 1(2), 39-49 (2017)

34. Raut, S., Thorat, P.V., Thakre, R.: Green synthesis of Zinc oxide $(\mathrm{ZnO})$ nanoparticles using Ocimum tenuiflorum leaves. Int. J. Sci. Res. 4(5), 1225-1228 (2013)

35. Awwad, A.M., Albiss, B., Ahmad, A.L.: Green synthesis, characterization and optical properties of zinc oxide nanosheets using Oleaeuropea leaf extract. Adv. Mater. Lett. 5(9), 520-524 (2014)

36. Lakshm, S.J., Roopa Bai, R.S., Sharanagouda, H., Ramachandra, C.T., Kumar Nidoni, U.: A review study of zinc oxide nanoparticles synthesis from plant extracts. Green Chem. Technol. Lett. 3(2), 26-37 (2017)

37. Luna-Vázquez, F.J., Ibarra-Alvarado, C., Rojas-Molina, A., RojasMolina, J.I., Yahia, E.M., Rivera-Pastrana, D.M., Rojas-Molina, A., Zavala-Sánchez, Á.M.: Nutraceutical value of black cherry Prunus serotina Ehrh. fruits: antioxidant and antihypertensive properties. Molecules 18(12), 14597-14612 (2013)

38. Mohd Omar, F., Aziz, H.A., Stoll, S.: Stability of ZnO nanoparticles in solution. Influence of $\mathrm{pH}$, dissolution, aggregation and disaggregation effects. J. Colloid Sci. Biotechnol. 3, 1-10 (2014)

39. Vasudevan, A., Jung, S., Ji, T.: Synthesis and characterization of hydrolysis grown zinc oxide nanorods. Int. Sch. Res. Not. (2011). https://doi.org/10.5402/2011/983181

40. Khalil, M.M.H., Ismail, E.H., El-Baghdady, K.Z., Mohamed, D.: Green synthesis of silver nanoparticles using olive leaf extract and its antibacterial activity. Arabian J. Chem. 7, 1131-1139 (2014)

41. Ghorbani, H.R., Mehr, F.P., Pazoki, H., Rahmani, B.M.: Synthesis of $\mathrm{ZnO}$ nanoparticles by precipitation method. Orient. J. Chem. 31(2), 1219-1221 (2015)

42. Dorraniana, D., Fotovat Eskandari, A.: Effect of laser fluence on the characteristics of $\mathrm{ZnO}$ nanoparticles produced by laser ablation in acetone. Mol. Cryst. Liq. Cryst. 607, 1-12 (2015)

43. Buazar, F., Bavi, M., Kroushawi, F., Halvani, M., Khaledi-Nasab, A., Hossieni, S.A.: Potato extract as reducing agent and stabilizer in a facile green one-step synthesis of $\mathrm{ZnO}$ nanoparticles. J. Exp. Nanosci. 11(3), 175-184 (2016)

44. Rafaie, H., Samat, N., Nor, R.M.: Effect of $\mathrm{pH}$ on the growth of zinc oxide nanorods using Citrus aurantifolia extracts. Mater. Lett. 137, 297-299 (2014)

45. Jain, P.K., Huang, X., El-Sayed, I.H., El-Sayed, M.A.: Review of some interesting surface plasmon resonance-enhanced properties of noble metal nanoparticles and their applications to biosystems. Plasmonics 3(2), 107-118 (2007)

46. Ishikawa, Y., Shimizu, Y., Sasaki, T., Koshizaki, N.: Preparation of zinc oxide nanorods using pulsed laser ablation in water media at high temperature. J Colloid Interface Sci. 300, 612-615 (2006)

47. Drmosh, Q.A., Gondal, M.A., Yamani, Z.H., Saleh, T.A.: Spectroscopic characterization approach to study surfactants effect on $\mathrm{ZnO}_{2}$ nanoparticles synthesis by laser ablation process. Appl. Surf. Sci. 256, 4661-4666 (2010)

48. Kiruba, V.S.A., Dakshinamurthy, A., Subramanian, P.S., Selvakumar, P.M.: Green synthesis of biocidal silveractivated charcoal nanocomposite for disinfecting water. J. Exp. Nanosci. 10(7), 532-544 (2013)

49. Oyetade, O.A., Oyeleke, G.O., Adegoke, B.M., Akintunde, A.O.: Stability studies on ascorbic acid (vitamin C) from different sources. IOSR-JAC 2(4), 20-24 (2012)

50. Vanaja, M., Rajeshkumar, S., Paulkumar, K., Gnanajobitha, G., Malarkodi, C., Annadurai, G.: Kinetic study on green synthesis of silver nanoparticles using Coleus aromaticus leaf extract. Adv. Appl. Sci. Res. 4(3), 50-55 (2013) 
51. Bar, H., Bhui, D.H., Sahoo, P.G., Sarkar, P., De, P.S., Misra, A.: Kinetic study on green synthesis of gold nanoparticles using bougainvillea Glabra leaf extract. Colloids Surf. A Physicochem. Eng. Asp. 339, 134-139 (2009)

52. Sharma, V.K., Yngard, R.A., Lin, Y.: Silver nanoparticles: green synthesis and their antimicrobial activities. Adv. Colloid Interface Sci. 145, 83-96 (2009)

53. Tessier, P.M., Velev, O.D., Kalambur, A.T., Rabolt, J.F., Lenhoff, A.M., Kaler, E.W.: Assembly of gold nanostructured films templated by colloidal crystals and use in surface enhanced Raman spectroscopy. J. Am. Chem. Soc. 122, 955-9555 (2000)

54. Annamalai, A., Thomas, S., Jose, N.A., Lyza, C.V.: Biosynthesis and characterization of silver and gold nanoparticles using aqueous leaf extraction of Phyllanthus amarus Schum \& Thonn. World Appl. Sci. J. 13(8), 1833-1840 (2011)

55. Brus, L.: Electronic wave functions in semiconductor clusters: experiment and theory. J. Phys. Chem. 90, 2555-2560 (1986)

56. Talam, S., Karumuri, S.R., Gunnam, N.: Synthesis, characterization, and spectroscopic properties of $\mathrm{ZnO}$ nanoparticles. Int. Sch. Res. Not. 2012, 1-6 (2012)

57. Jamdagni, P., Khatri, P., Rana, J.S.: Green synthesis of zinc oxide nanoparticles using flower extract of Nyctanthes arbor-tristis and their antifungal activity. J. King Saud. Univ. Sci. 4(5), 121-132 (2016)
58. Zheng, Y., Fu, L., Han, F., Wang, A., Cai, W., Yu, J., Yang, J., Peng, F.: Green biosynthesis and characterization of zinc oxide nanoparticles using Corymbia citriodora leaf extract and their photocatalytic activity. Green. Chem. Lett. Rev. 8(2), 59-63 (2015)

59. Sadollahkhani, A., Kazeminezhad, I., Lu, J., Nur, O., Hultman, L., Willander, M.: Synthesis, structural characterization and photocatalytic application of ZnO@ZnS core-shell nanoparticles. RSC Adv. 4, 36940-36950 (2014)

60. Varghese, E., George, M.: Green synthesis of zinc oxide nanoparticles. Int. J. Adv. Res. Sci. Eng. 4(01), 307-314 (2015)

61. Namvar, F., Azizi, S., Rahman, H.S., Mohamad, R., Rasedee, A., Soltani, M., Rahim, R.A.: Green synthesis, characterization, and anticancer activity of hyaluronan/zinc oxide nanocomposite. Onco Targets Ther. 9, 4549-4559 (2016)

62. Kaviyarasi, T., Muthulakshmi, B., Kavitha, C.: Green synthesis and characterization of zinc nanoparticle using Aegle marmelos leaf extract. Int. J. Chem. Technol. Res 10(15), 344-348 (2017)

Publisher's Note Springer Nature remains neutral with regard to jurisdictional claims in published maps and institutional affiliations. 